\title{
Os desafios do século XXI
}

\author{
WASHINGTON NOVAES
}

$\mathrm{P}$ OR QUALQUER ângulo que se aproxime do tema, qualquer que seja o nó que se tente desfazer, constata-se que, para vencer os grandes desafios que terá no século XXI, o Brasil deverá mudar radicalmente sua postura - colocar a questão ambiental no início e no centro de todas as políticas, para que ela perpasse todas as concepções e todas as ações. Se não for assim, caminhará de precariedade em precariedade, retornará sempre a um ponto de partida cada vez mais complexo e grave.

Pode-se começar pelo desafio que está sendo considerado o mais grave e imediato de todos - superar os constrangimentos nas contas externas do país. Para isso, teríamos de dobrar as exportações, de modo a obter um saldo comercial que nos permitisse suportar as contas deficitárias de juros, remessa de lucros, royalties, assistência técnica, viagens etc.

Mas a prática está mostrando um quadro bem diferente. Partiu-se da previsão de um saldo comercial de US\$ 10 bilhões, que foi minguando. E já se admite até a possibilidade de déficit comercial em 2000.

Não é exatamente surpresa. Desde os primeiros anos da década de 90, seguidos diagnósticos têm apontado a falta estrutural de competitividade das exportações brasileiras. Essencialmente, por falta de inovação tecnológica real. Para compensar, recorre-se à apropriação de fatores ambientais, como se fossem financeiros. E à mão-de-obra barata, aos salários reais deprimidos. É o que diz, por exemplo, o Relatório do Desenvolvimento Humano no Brasil (PNUD, 1996).

Só que custos ambientais e custos sociais costumam ter preços altos, ao longo do tempo. São finitos, esgotam-se. E mesmo quando a competitividade é assim obtida, a falta de escala para competir leva a outro obstáculo quase insuperável.

Outro documento mais recente - Agenda 21 Brasileira-Bases para Discussão - confirma esse diagnóstico.

Esse documento é fruto de exaustivas discussões e análises no âmbito da Comissão de Políticas de Desenvolvimento Sustentável (CPDS) e da Agenda 21 Nacional, criada pelo governo federal, mas que é paritária - além de membros do governo, tem representantes do empresariado e da sociedade. 
A CPDS contratou, por licitação, seis diagnósticos setoriais: agricultura sustentável; gestão de recursos naturais; cidades sustentáveis; redução das desigualdades sociais; infra-estrutura e integração regional; ciência e tecnologia. Após as discussões desses seis diagnósticos em seminários regionais e num seminário nacional, em Brasília, eles foram sistematizados naquele documento, que está agora em cada estado e ainda será debatido em outro seminário nacional. Ao fim deste, ter-se-á uma proposta de Agenda 21 brasileira, de desenvolvimento sustentável para o país.

O diagnóstico de ciência e tecnologia do documento sistematizado confirma a visão mencionada. Chama de "espúrios" os fatores ambientais e de custo rebaixado de mão-de-obra a que se recorre para obter competitividade nas exportações - com graves implicações sociais e ambientais.

É um diagnóstico que pode ser confirmado ainda, sem dificuldade, por um exame, mesmo que rápido, da realidade.

Nas exportações agrícolas, por exemplo, mesmo com as commodities alcançando seu mais baixo preço em 150 anos - ou talvez por isso mesmo -, continua-se recorrendo à apropriação de custos ambientais como se fatores financeiros fossem. Em boa parte do agribusiness, um dos custos do modelo é uma taxa brutal de erosão, que pode chegar a 10 quilos de solo perdidos por quilo de grão produzido e a uma perda anual de um bilhão de toneladas de solo por ano, segundo documentos governamentais. Solo cuja fertilidade terá de ser reposta por insumos químicos, de alto custo, mas que não melhorarão o preço das commodities exportadas.

Por esse caminho - um dos muitos - paga-se aqui o custo ambiental, que deveria caber aos países importadores desses produtos. Não pagam. E mantêm a competitividade de seus produtos - carnes, entre vários outros por essa via. E ainda não é o único custo.

O modelo de desmatamento intensivo - para que haja mecanização intensiva -, aliado à aração e revolvimento da terra na entressafra, deixa o solo exposto à erosão pelas chuvas, pelos ventos e pelo sol. O solo carreado para os cursos d'água desprotegidos vai assorear os leitos e degradar os recursos hídricos, inclusive pela carga de agrotóxicos. O custo pode ser estratosférico, como demonstra o caso do Oeste catarinense.

Mas há mais ainda. O mesmo modelo de mecanização intensiva é causa determinante do êxodo rural, uma das razões para o aumento brutal da população urbana no país, com toda a seqüela de acontecimentos que determinou e determina. 
Nos 36 anos que vão do Censo de 1960 à contagem populacional de 1996, a população urbana brasileira cresceu mais de 90 milhões de pessoas (31,3 milhões para 123 milhões), enquanto a rural caía de 38,7 milhões para 33,9 milhões. No Centro-Oeste, exemplo dramático, acompanhando a chamada expansão da fronteira agrícola, a população urbana nesse período passou de um milhão para 8,8 milhões, enquanto a rural decrescia de 1,9 para 1,6 milhão. Embora as fortes taxas de natalidade nesse período respondam por uma parte do crescimento populacional urbano, a elas se somaram os índices migratórios.

Nas grandes cidades, esse movimento correspondeu à expansão desordenada das periferias, onde a especulação imobiliária transferiu para um poder público exaurido os custos de implantação de todas as infra-estruturas - de transportes, energia, abastecimento e saneamento básico, educação, saúde, limpeza urbana, lazer etc. A implantação não aconteceu, na maior parte dos casos, gerando o quadro de difícil abordagem observado hoje, que culmina na insegurança ampla aliada ao desemprego e a outras carências.

Além do mais, essa expansão urbana gerou a devastação ambiental e a ocupação de áreas de risco e/ou de preservação permanente. Simultaneamente, seguiu o processo de assoreamento dos rios, agora pela deposição de esgotos não-tratados, erosão de margens desprotegidas e carreamento do lixo não-recolhido.

O quadro periódico de inundações que se tornou familiar às grandes cidades brasileiras no período de chuvas é um dos resultados finais de todo o processo, fruto ainda da impermeabilização progressiva do solo urbano - e esta, conseqüência do descaso na fiscalização dos códigos de obras que exigem a manutenção de áreas permeáveis. Soma-se a tudo a progressiva ocupação das margens de rios, áreas de inundação natural, por grandes vias expressas. E chega-se ao panorama caótico das temporadas de verão, com as grandes cidades submetidas a inundações freqüentes, não raro simultâneas, a racionamento no abastecimento de água - já que não podem ser utilizados os mananciais que cortam o território urbano, tal sua carga de poluição.

A ocupação inadequada do solo - rural e urbano - é uma das características mais fortes do modelo brasileiro hoje. Nas áreas urbanas, as matrizes de transportes e de energia, combinadas, levaram ao contra-senso de mais de 50\% do solo estarem, segundo a Associação Nacional de Transportes Públicos, ocupados por vias de transporte ou instalações auxiliares (estacionamentos, garages etc.). O que deveria ser meio transforma-se em fim em si mesmo. E gera os transtornos dos congestionamentos, dos rodízios, da lentidão dos deslocamentos. 
Simultaneamente, a matriz de transporte, baseada fundamentalmente em combustíveis fósseis, não tem seus custos contabilizados - nem na manutenção/expansão da malha viária, nem quanto aos elevados níveis de poluição atmosférica, que geram outros custos nas redes pública e privada de saúde, na redução de produtividade no trabalho (mais tempo em deslocamentos para cumprir a mesma tarefa) etc. Se esses custos fossem contabilizados talvez nos aproximássemos da viabilização de fontes alternativas de energia, hoje consideradas "mais caras".

Os problemas com a matriz energética brasileira não se esgotam aí - longe disso.

O mencionado documento da Agenda 21 brasileira recomenda expressamente que a prioridade no país no setor energético seja conferida à conservação de energia, não à expansão da oferta. Por uma razão simples: a conservação de um quilowatt de energia custa algumas vezes menos que a geração de um quilowatt novo (o cálculo varia, segundo os autores, entre cinco e 10 vezes, dependendo de vários fatores). E os desperdícios e perdas na matriz brasileira são alentados. Segundo a Eletrobrás, significam, só os desperdícios, R\$2,8 bilhões/ano. As perdas na matriz, 15,5\% do total gerado.

A discussão sobre o tema no país, ao longo dos anos, tem envolvido por um lado a ameaça de déficits e racionamentos que nunca se concretizam, e por outro a concepção enganosa de que conservar energia significa apenas não utilizar o chuveiro elétrico nos horário de píco ou fechar corretamente a porta do refrigerador. Muitos outros ângulos precisariam ser considerados:

- já no final da década passada, uma consultoria contratada pela Eletrobrás apontava a possibilidade de reduzir o consumo em até $20 \%$ na década seguinte, a um custo que corresponderia a um quinto do custo previsto para a expansão do sistema; e lembrava: investimentos em energia significam menos investimentos em educação, saúde, habitação; a redução do consumo de energia aumenta também a competitividade dos produtos exportáveis;

- essa possibilidade foi claramente demonstrada, por exemplo, após o choque do petróleo, nos Estados Unidos, onde a economia entre 1974 e 1988 cresceu $35 \%$, sem aumentar um só quilowatt no consumo de energia elétrica, embora no período se construíssem milhões de residências e de áreas comerciais e industriais;

- apesar disso, os orçamentos do setor elétrico brasileiro destinam aos programas de conservação de energia frações mínimas (e nem essas 
porcentagens se concretizam), para economizar $0,25 \%$ do consumo anual, que, ao final de 20 anos, representariam $5 \%$ do consumo - que é a taxa anual prevista para expansão da demanda;

- a discussão no Brasil precisaria abranger também a possibilidade de um terceiro turno em atividades industriais e comerciais, sem custo de expansão da oferta de energia, já que nos horários da noite e da madrugada a sobra de energia no sistema chega até a $80 \%$.

- seria preciso discutir também o modelo que confere prioridade às grandes geradoras, com o conseqüente nível alto de perdas.

Ângulo particularmente complicado é o do subsídio aos produtos eletrointensivos, como alumínio, silício metálico, gusa, que consomem, por exemplo, $50 \%$ da energia gerada em Tucuruí. São produtos que têm tarifa elétrica subsidiada entre 30 e $66 \%$, com prejuízo de subsídios contabilizado (em 1997) de R\$ 200 milhões/ano.

Trata-se de produtos cuja fabricação os países industrializados vêm abandonando progressivamente, dados seus altos custos ambientais e energéticos (no alumínio, por exemplo, a energia representa $47 \%$ do custo final). O Japão, um desses casos, produzia 1,1 milhão de toneladas de alumínio por ano. Baixou a produção para apenas 41 mil toneladas/ano, destinadas a um estoque estratégico, e passou a importar o restante, inclusive do Brasil.

É mais um dos casos em que se transferem para o país exportador, sem compensação, os custos ambientais e econômicos.

Da produção brasileira de alumínio ( 1,1 milhão de t/ano), mais de $70 \%$ (794 mil t) destinam-se à exportação. E planejamos exportar mais: a vazão do rio Tocantins foi regularizada pela construção da hidrelétrica de Serra da Mesa, que, além de gerar energia (com enormes custos ambientais em seu reservatório de $1.784 \mathrm{~km}^{2}$ ), permitirá construir novas barragens rio abaixo e duplicar a produção em Tucuruí (onde metade da energia já se destina aos eletrointensivos).

O questionamento de novas barragens não ocorre apenas pelo ângulo das perdas e desperdícios na matriz energética - cuja eliminação deveria ser prioritária. Vem também pelo ângulo ambiental.

As 800 mil barragens que hoje existem no mundo têm reservatórios, que, juntos, formariam um território maior que o da França. Só barragens acima de 15 metros são 45 mil (no Brasil, mais de 500). A construção dessas barragens deslocou mais de 10 milhões de pessoas. 
Tucuruí, com seu reservatório de $2.875 \mathrm{~km}^{2}$, deslocou mais de 40 mil pessoas, sepultou 2,9 milhões de $\mathrm{m}^{3}$ de madeira tropical, inviabilizou a pesca a jusante, disseminou a malária, concentrou mercúrio em níveis cinco vezes acima do máximo permitido legalmente.

As barragens, principalmente em áreas de floresta, estão sofrendo contestação progressiva. Uma das razões está na liberação, pela matéria orgânica retida pelos reservatórios e em decomposição, de mais dióxido de carbono e metano (este último, 20 vezes mais prejudicial que o outro, em termos de contribuição para o efeito estufa) que uma termelétrica de igual porte. Um dos exemplos que têm sido citados pela Comissão Mundial de Barragens é o da hidrelétrica de Balbina, que libera três milhões de toneladas de $\mathrm{CO}_{2}$ por ano, quase 10 vezes mais que uma termelétrica de igual porte.

Argumentos desse tipo reforçam as dúvidas com relação ao programa de implantação de novas e grandes geradoras hidrelétricas na região amazônica.

A Amazônia talvez seja, na verdade, o maior dos desafios que o país terá de enfrentar no século XXI. E para o qual parece não haver ainda estratégia definida.

A maior parte dos estudos sobre a região aponta a inadequação da quase totalidade dos solos para um modelo agropecuário tradicional. Ainda assim, os programas oficiais brasileiros continuam a prever a abertura de novos "eixos" de penetração, na verdade corredores destinados a facilitar a expansão dessa fronteira agropecuária, com produção destinada essencialmente à exportação e com os inconvenientes já mencionados.

Por outro ângulo, só recentemente o Ministério de Assuntos Fundiários proibiu por portaria novos assentamentos de reforma agrária em áreas de floresta primária. Já em 1997, uma

Comissão Externa da Câmara dos Deputados apontava, em relatório sobre a atuação de madeireiras estrangeiras na região, que os assentamentos de reforma agrária eram

\section{$88,15 \%$ das terras destinadas à reforma agrária estavam na Amazônia ...} responsáveis por mais de $50 \%$ do desmatamento na Amazônia. Nos últimos 30 anos, 88,15\% das terras destinadas à reforma agrária estavam na Amazônia. E a razão é simples: trata-se da área com menor resistência política e empresarial às desapropriações, além de a que mais terras públicas contém.

O processo é conhecido. Definida uma área para o assentamento, os lotes são demarcados e os assentados para eles encaminhados. Sem recur- 
sos, sem crédito e sem assistência técnica, os assentados fazem acordos com madeireiras para que derrubem a floresta e abram espaço à casa, às roças de "lavoura branca" e às pastagens. Ao fim de algum tempo, vendem ou alugam o lote para um fazendeiro vizinho e saem em busca de novo lote, onde reproduzirão o procedimento. É o que se chama de "desmatamento itinerante". Em alguma medida, o processo reproduz-se também nos cerrados, onde a proibição de assentamentos em área de vegetação nativa não vigora.

\section{$80 \%$ da madeira amazônica continuem a ser extraídos ilegalmente ...}

As atuais políticas brasileiras não conseguiram ainda sequer encontrar formatos que levem a um uso sustentável da madeira na região amazônica. Admite-se plenamente que pelo menos $80 \%$ da madeira amazônica continuem a ser extraídos ilegalmente e em grande parte exportados. O processo dá forte contribuição às queimadas, no chamado "arco do desmatamento", por abrir caminho ao fogo com a derrubada e abandono da vegetação de menor porte.

Um problema adicional, principalmente nos cerrados, está na degradação e/ou esgotamento dos recursos hídricos, dadas as mudanças no uso da terra - problema para o qual se dispõe de pouquíssima informação sistematizada e que também constituirá enorme desafio para as próximas décadas. Juntamente com políticas de proteção aos biomas, de modo a permitir que eles continuem prestando os serviços naturais (fertilidade do solo, recursos hídricos, conservação da vida nos manguezais, absorção de carbono etc.), de valor estimado pelo Ibama em $\mathrm{R} \$ 4$ trilhões, pelo menos cinco vezes o Produto Interno Bruto nacional.

Tanto nos cerrados quanto na Amazônia estão diante de todos os desafios de definir políticas adequadas para a conservação e o uso sustentável da biodiversidade, a mais rica do planeta, fonte dos futuros medicamentos, dos novos alimentos, dos novos materiais que substituirão os que se esgotarem. Da mesma forma, o desafio de definir uma política de conservação e uso sustentável para esses biomas - que substitua o atual vale tudo, onde as migrações constituem um precaríssimo substituto para a ausência de políticas de renda e emprego.

Em síntese, o grande desafio brasileiro para o século XXI será definir e executar uma política de desenvolvimento verdadeiramente sus-

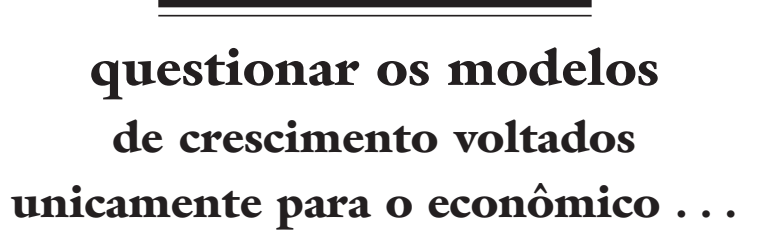


tentável - enfrentando inclusive a difícil tarefa de questionar os modelos de crescimento voltados unicamente para o econômico e descuidados do ambiental e social. Lembrando que por isso mesmo temos alguns dos piores indicadores de concentração de renda no mundo.

Para isso, entretanto, terá também de reexaminar sua inserção internacional, como recomenda o documento da Agenda 21.

Hoje, os países industrializados, com 19\% da população mundial detêm, segundo o PNUD, $86 \%$ do produto e do consumo, $82 \%$ das exportações, $71 \%$ do comércio mundial, 68\% dos investimentos diretos, 74\% linhas telefônicas e 93,3\% dos usuários da Internet. Os 10 países mais ricos detinham, já em 1993, mais de 80\% dos gastos mundiais com pesquisa e desenvolvimento. Controlavam 95\% das patentes registradas nos Estados Unidos e $80 \%$ das concedidas nos países em desenvolvimento - a concentração do conhecimento, na chamada "era do conhecimento".

A concentração da renda no mundo, segundo o mesmo PNUD, também é avassaladora. As três pessoas mais ricas do planeta, juntas, detêm ativos superiores ao produto interno bruto dos 48 países mais pobres, juntos, onde vivem cerca de $10 \%$ da humanidade (600 milhões de pessoas). Já as 200 pessoas mais ricas, cada uma delas com ativos superiores a US\$ 1 bilhão, detêm, juntas, mais que a renda anual de $45 \%$ da humanidade. Essas 200 pessoas em quatro anos aumentaram seus ativos - já superiores a US\$ 1 trilhão - em cerca de $150 \%$.

Em conseqüência desse quadro, diz o PNUD, uma criança nascida hoje em Nova York, Londres ou Paris, por sua capacidade de consumo, terá um impacto sobre os recursos naturais, ao longo de sua vida, 50 vezes mais forte que o de uma criança nascida nos países mais pobres. Que acontecerá com esses recursos naturais se esse padrão de consumo for estendido aos $80 \%$ da população que vivem nos países ditos em desenvolvimento?

"Isso é insustentável e não deve ser sustentado", diz o PNUD.

Se se olhar para dentro do país, o panorama tem suas semelhanças. Os $10 \%$ mais ricos da população brasileira tinham em 1995 cerca de $63 \%$ da renda, enquanto os $50 \%$ mais pobres detinham $11,6 \%$. E com o processo se agravando.

Cabe, então, reexaminar tudo. Até porque a própria governabilidade está em risco. E "sem governabilidade forte o perigo de conflitos globais será uma realidade no século XXI - guerras comerciais para promover interesses nacionais e corporativos, volatilidade financeira descontrolada, 
infectando vizinhos sadios e inviabilizando a política, os negócios e a segurança" (PNUD, 1999).

Como tem escrito o jurista José Eduardo Faria, a volatilidade dos mercados financeiros - que já acumulam mais de US\$ 70 trilhões, o triplo do PIB anual do mundo - obriga os governantes a trabalhar com a atenção permanentemente voltada para os computadores que registram 24 horas/ dia as mudanças nos mercados de câmbio, de juros e de mercadorias futuras no mundo todo. Obrigados também a reagir instantaneamente, para defender-se. Mas esse tempo imediato elimina a possibilidade de outro tempo mais lento, que é o tempo da negociação, da discussão, da formação de consensos, que a política exige. E se o tempo da política é eliminado, elimina-se o tempo da democracia, dos direitos humanos, da justiça social. O Estado só terá, para relacionar-se com a sociedade, o braço da segurança.

É diante desses desafios que o Brasil está colocado, ao ingressar no século XXI. Ser capaz de enfrentá-los exigirá, antes de tudo, que o país seja capaz de mudar seus hábitos e formatos políticos, que começam pela nãoexplicitação de conflitos.

Todos os conflitos terão de ser explicitados. Para que as partes se sentem à mesa e produzam formatos negociados, a serem traduzidos em programas de desenvolvimento sustentável e de governo - com apoio da sociedade.

Se não for assim, viveremos dias cada vez mais difíceis.

Washington Novaes, jornalista, é consultor ambiental e ex-secretário estadual de Meio Ambiente, Ciência e Tecnologia de Brasília (DF). 